\title{
A Child with 5q Deletion and Accompanying Chiari 1 Malformation
}

\author{
Emine Ikbal Atli ${ }^{1}$ (D) Sinem Yalcintepe ${ }^{1}$ (D) $\cdot$ Engin Atli ${ }^{1}$ (D) $\cdot$ Selma Demir $^{1}$ (D) $\cdot$ Hakan Gurkan $^{1}$ (D)
}

Received: 4 February 2020 / Accepted: 9 July 2020 / Published online: 16 July 2020

(C) Dr. K C Chaudhuri Foundation 2020

To the Editor: We present a 1-y-old girl who had been detected to have a $\sim 13 \mathrm{Mb}$ deletion on chromosome 5q11.2, and was referred to from pediatrics with Chiari 1 malformation. Prescott et al. have firstly described 5q11.2 microdeletion syndrome [1].

The patient was the second healthy child of nonconsanguineous parents. She was the 3rd pregnancy of the mother; 2nd pregnancy resulted in abortion. She had a healthy elder brother of $5 \mathrm{y}$. She was born by cesarean section at the 39th wk of pregnancy. Birth parameters were within normal range. Choanal atresia was noted at birth. She had nasal surgery at $8 \mathrm{~d}$ of age. She was found to have nystagmus and hypermetropia. Prominent nasal root/broad nasal bridge, micrognathia, retrognathia and long filtrum and a high/ narrow palate were detected. She had bilateral dysplastic ears. Her second toe was overlapping with third toe, on the left foot. Developmental Quotient (DQ) was calculated as $>85$. Brain MRI showed, mild ventricular dilatation without parenchymal loss with Chiari 1 malformation [2].

The karyotype analysis revealed 46,XX,del(5)(q11.2q12.1). Whole genome array comparative genomic hybridization $(\mathrm{aCGH})$ was performed on an Agilent $4 \times 180 \mathrm{~K}(\mathrm{CGH}+$ SNP) array slide. It revealed a clinically significant $\sim 13 \mathrm{Mb}$ deletion at $5 \mathrm{q} 11.2 \mathrm{q} 12.1$ starting from 50.288.355 to 63.149.770 bp. Parents' karyotypes and aCGH results were normal. So the deletion was specified as de novo. We used a next-generation sequencing (NGS) panel, targeting 49 genes mutated in autism spectrum disorder but it did not reveal any pathogenic variants.

To date, only 13 cases of $5 \mathrm{q} 11.2$ microdeletion have been reported [2]. Although no different phenotype has been identified for this microdeletion syndrome, published cases share many common clinical features [3, 4]. Dysplastic-ears,

Emine Ikbal Atli

emine.ikbal@gmail.com; eikbalatli@trakya.edu.tr

1 Department of Medical Genetics, Trakya University Faculty of Medicine, Edirne, Turkey micrognathia, hypermetropia, central nervous system (CNS) malformations were evaluated as concurrent findings with the literature in our patient. Among the cases in the literature, development delay (DD) in $\sim 91 \%$, intellectual disability (ID) in $\sim 67 \%$, CNS anomalies in $\sim 64 \%$ and facial dysmorphism was reported in almost all patients. However, Chiari 1 malformation has been reported for the first time in our case. Some genes that are included in the deleted region are known to be expressed in the CNS and that could potentially cause the anomalies [5]. More studies are needed to demonstrate the effects of the other genes in $5 \mathrm{q} 11$.

\section{Compliance with Ethical Standards}

Conflict of Interest None.

\section{References}

1. Prescott K, Woodfine K, Stubbs P, et al. A novel $5 \mathrm{q} 11.2$ deletion detected by microarray comparative genomic hybridization in a child referred as a case of suspected $22 \mathrm{q} 11$ deletion syndrome. Hum Genet. 2005;116:83-90.

2. Arora V, Aggarwal S, Bijarnia S, et al. Extending the phenotype and identification of a novel candidate gene for immunodeficiency in 5q11 microdeletion syndrome. Mol Syndromol. 2019;9:312-8.

3. Fontana P, Tortora C, Petillo R, et al. A novel 5q11.2 microdeletion in a child with mild developmental delay and dysmorphic features. Am J Med Genet A. 2016;170:2445-8.

4. Capra V, Iacomino M, Accogli A, et al. Chiari malformation type I: what information from the genetics? Childs Nerv Syst. 2019;35: 1665.

5. Gnan C, Franzoni A, Baldan F, Passon N, Damante G, Dello Russo P. Familial 5q12.3 microdeletion: evidence for a locus associated with epilepsy. Mol Syndromol. 2017;8:98-102.

Publisher's Note Springer Nature remains neutral with regard to jurisdictional claims in published maps and institutional affiliations. 